\title{
Human factor in professional activity of aviation maintenance specialists as an element of flight security
}

\author{
Liudmila Dotsenko ${ }^{1}$, Inna Kariaka ${ }^{1}$, and Serhii Yahodzinskyi ${ }^{2, *}$ \\ ${ }^{1}$ National Aviation University, Liubomira Guzara av., 03058, Kyiv, Ukraine \\ ${ }^{2}$ International European University, Vernadskogo av., 02000, Ukraine
}

\begin{abstract}
Target of this article is to consider particularities of human factor influence in professional activity of aviation maintenance specialists. In consequence of theoretic analysis of studying of this problem were discovered preconditions and recent trends of development of human factor at specialists of this activity area as well as were identified structural components of mentioned phenomenon. According to that, the authors made a description of defining characteristics of manifestation of human factor in professional activity of aviation maintenance specialists: psychophysiological particularities of employees, professional requirements for carrying out of this activity and work conditions of those specialists. All this, at the opinion of authors, is one of determinants of human factor manifestation at aviation maintenance specialists. As to the improvement of professional activity level of specialists of this field, following levels of human factor manifestation at aviation maintenance specialists with precise hierarchic structure of its development were identified: sensory-perceptual level (work of human analyzer system), personal level (value-motivational aspect of carrying out of professional activity) and professional level (development of professional competence of personnel). At the basis thereof it was elaborated authors functional three-stage hierarchic model of human factor of aviation maintenance specialists. In order to decrease the risk of mistakes making by specialists during solving professional problems at any level of their committing, it was suggested a number of activities for improvement of human factor in professional activity of aviation maintenance specialists, which are directed to the development of sensoryperceptual, personal and professional levels.
\end{abstract}

\section{Introduction}

Dynamic development of society favours the appearance of scientific interest related to the study of human factor during elaboration and taking decisions both at mundane and professional levels. This problem is particularly important in aviation area, as far as the flight operations security is the main purpose of aviation maintenance specialists. [1] The reason for this is that from the acts of the crew, flight operations officer, employees of aircraft

\footnotetext{
* Corresponding author: yahodzinskyi.serhii@gmail.com
} 
technical maintenance depends the degree of risk of creation of crush situations, accidents and incidents. For this very reason the problem of study of human factor of aviation maintenance specialists under nowadays conditions is a key issue of theoreticians and practitioners of technical and humanitarian areas not only in Ukraine but also worldwide.

Formulation and giving meaningful content to the notion in aviation area was being made throughout the history of its formation and development, as this definition personifies a system, difficult enough, of relations "humans-aircraft-environment", the key centre of which are humans. The reason for this is that notably humans are the most flexible elements of the aviation system, which is able to adapt and at the same time is the most vulnerable in terms of possibility of negative influence on his activity. Except for that, the presence of complex system relations between aviation services, organizations, institutions led to the understanding of necessity of goal-oriented study of professional environment and effective management of different kinds of aviation activity. [4]

Study of "human factor" in aviation is associated with the name of soviet doctor - aviator M M Dobrotvorskyi. Specifying the conditions of aircraft safe operation, he notes that the flight safety relates to the ability of adaptation of the equipment itself to humans: "Requirements to humans may be fixed only after the aircraft is adapted to average person" [5]. That is to say that the main thing in the equipment to be fabricated is the comfort of the person that will use it.

It has to be noted that sufficient period of time in aviation the study of human factor concerned mainly the system "Pilot-Cabin", but underestimation of influence of this phenomenon in the activity of aviation maintenance specialists is dangerous enough. It is due to the fact that the safety and reliability of operations of aviation technical maintenance depends on humans no less than on aircraft's technical systems and the mistakes of engineering personnel often lead to the same disastrous consequences as the mistakes of pilots. [3]

According to data of the National Bureau of Air Accidents Investigation (NBAAI) over the period 2015-2019, a positive dynamic was recorded as to the decrease of number of accidents, emergency situations and incidents during flights. [6] Statistical data are shown in table 1 .

Table 1. Incidents with aircrafts during transportation and passenger operations over the period $2015 / 2019$

\begin{tabular}{|c|l|c|c|c|c|c|}
\hline \multirow{2}{*}{ № } & \multirow{2}{*}{ Events classification } & $\mathbf{2 0 1 9}$ & $\mathbf{2 0 1 8}$ & $\mathbf{2 0 1 7}$ & $\mathbf{2 0 1 6}$ & $\mathbf{2 0 1 5}$ \\
\cline { 3 - 7 } & & 2 & 2 & 2 & - & - \\
\hline 1 & Crashes & 3 & 3 & 2 & 4 & 1 \\
\hline 2 & Accidents & 3 & 4 & 4 & 4 & 2 \\
\hline 3 & Serious incidents & 31 & 57 & 41 & 21 & 30 \\
\hline 4 & Incidents Total events & 39 & 66 & 49 & 29 & 33 \\
\hline \multicolumn{7}{|c|}{ Number of victims } \\
\hline \multicolumn{7}{|c|}{} \\
\hline 5 & Killed & 6 & 24 & 2 & 7 & 5 \\
\hline 6 & Injured & 3 & 3 & 1 & 0 & 13 \\
\hline
\end{tabular}

According to the data of this table, it seems fair to say that in 2019 during operation of transportation flights by aircrafts (AC) registered in Ukraine registration, relative figures of safety status compared to the last years decreased, even though the difference between these figures is not important. However it is worth to notice that the percentage of reasons that led to such consequences is attributed to the human factor. It is confirmed by statistical data of the NBAAI: among factors causing crashes, accidents and serious incidents, $53 \%$ belong to the human and organization factor, in $18 \%$ cases the factors are not determined, $10 \%$ are environment factors and $9 \%$ are technical ones. 
According to this, the goal of this article is to clarify the results of study of human factor in aviation area in order to optimize the interaction in the system "humans-aircraftenvironment". The subject matter of the study is the regularities of behaviour reactions of humans in various professional situations.

Taking into account the above, it should be noted that human factor in aviation is a polymodal phenomenon that allows to describe the possibility for any participant preparing the flight to take erroneous or analogous decisions in specific situations. This thesis is explained by the fact that each participant of the system of aviation safety management has certain restriction as to the use of his possibilities. This being said, not always psychological and physiological characteristics of these persons correspond to the complexity level of problems and tasks to be resolved. For this very reason, each of them is in the group of risk of making mistakes during execution of certain functions being the expression of human factor.

\section{Materials and Methods}

Study of mentioned problem was carried out using following scientific methods:

- theoretic: analysis, classification, systematization, comparison and generalization of theoretic, statistical and experimental data of the problem of study;

- empiric: supervision, the target of which was to identify the applied aspect of manifestation of human factor in professional activity of aviation maintenance specialists; simulation, at the basis of which was elaborated a functional model of human factor of aviation maintenance specialists.

\section{Results}

As a result of our theoretical analysis, it was discovered main factors of influence of human factor of aviation maintenance specialists among which the main place is occupied by specific conditions of work and qualification requirements. The first ones generate functional changes that go outside the framework of physiological variation and increase the risk of deterioration of health: lighting, that is very difficult to assure during carrying out of all technical inspection operations, including verification of quality of conducted works (during investigation of aviation accidents, work of technical inspection being conducted in the open air at night time); works of technical inspection related to the use of some kinds of tools where out-dated control and inspection equipment is mainly intended for the mastery of specialists, which are working therewith, for ability to read and to interpret correctly ambiguous and sometimes contradictory readings; noise, caused by such works as engine starting and run, verification of working ability of electric actuators etc. At the same time technicians of aviation inspection shall execute a number of tasks, obligations, according to qualification requirements of occupied position. Mentioned factors lead to the deterioration of physical condition of specialists, extinction of psychological functions that increase the risk of making mistakes, which affect technical aviation inspection.

Informative survey of theoretic and applied aspects of human factor of aviation maintenance specialists provides the opportunity to note that identified factors, which cause inadvertency of employees during works executions, belong to different areas of human life and activities.

On physiological level professional activity of technical personnel is dominated by the sight, as the specialist of this area receives $90 \%$ of information through optic foramen. With the help of sight the employee becomes acquainted with documents, makes diagnosis of faults, evaluates the scope of work, executes precisely the most difficult types of this work. 
That is to say that from the quality of organization of "visual acquaintance" depends the quality of execution of professional task. Its dysfunction leads to extraocular muscles strain, decrement in visual acuity, increase of eye blink rate causes a discomfort of visual perception of employees, provokes fatigue, irritation, and, consequentially, increases the risk to make more mistakes during execution of repair operations. A great significance as to the quality of execution of professional activity of technical personnel has the hearing. It is known that human acoustic analyzer is capable to perceive sensitive sound with frequency from $16 \mathrm{~Hz}$ till $20 \mathrm{kHz}$, however, taking into account the specificity of work conditions of the employees, very often these standards are violated. And this, in its turn, leads to extraneous noise appearing, which is the reason of decrease of concentration, the consequence of which is the work decrement and increase of mistakes number. Mentioned physiological components of human factor cause failure at sensory-perceptual level, as a result of which a person may develop illusory perception of reality. That is to say, during carrying out of repair operations, the employee may, having overlooked the size of certain part, mistake the tool for its screwing and damaged the features of the thread of nut, screw or stud.

Particularities of manifestation of human factors at sensory-perceptual level favour the updating of value-motivational and cognitive processes of individual. Thus, quite often conditions and specificity of professional activity of technical personnel may cause certain difficulties of mentioned components of personal level of human factors manifestation. Reasons of these complications may arise at different levels: informational, organizational. That is to say that during execution of certain operations in case of insufficient awareness a person may develop certain emotional states, which block the activity of cognitive and personal functions. And this leads to the occurrence at the employee of so-called existentialist block, which is characterized by loss of sense of any thing, including fulfilment of his professional obligations. Due to passive work of cognitive processes caused by being under acedia, depression state, state of frustration, it can be observed the perversion of the sphere of personality values and senses. And this, in its turn, increases the risk of mistakes making during execution of repair operations.

Professional level of human factor manifestation is determined by the presence of professional interest at technical personnel during execution of repair operations, affection and will to improve their knowledge through professional training (upgrade training), as well as improvement of professional skills at the basis of permanent updating of knowledge. It means that permanent updating and improvement of equipment requires from maintenance personnel the updating of knowledge and skills, which would allow to fully execute repair operations. However, over and over again, employees with experience over 20 years have difficulty in updating of certain professional knowledge, which leads to decrease of quality of executed operations. Apart from that, the work conditions (routine work, absence of appropriate equipment, particularity of construction itself etc.) also favour its decrease. [10]

Summarizing the above, it should be noted that identified levels of human factors manifestation at aviation maintenance specialists have a hierarchic structure of its manifestation. That is to say that appearance of sensory-perceptual level of these factors (functioning of visual and acoustic analyzer) is only a releaser of this powerful system. At that, personal factor acts as an intermediary of mentioned factors and the professional one is the highest degree if their manifestation. Graphic picture of functional model of human factor at aviation maintenance specialists is represented in figure 1 . 


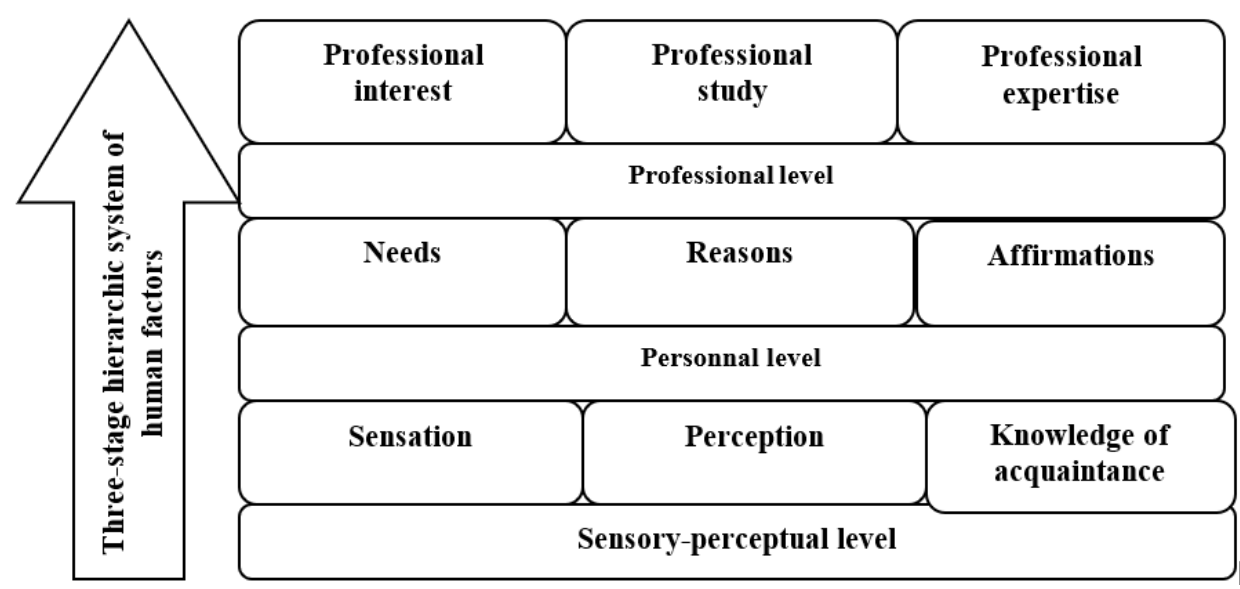

Fig. 1. Functional model of human factor of aviation maintenance specialists.

According to the above, it may be said that functioning of human factor of technical personnel has a three-stage hierarchic system executed at sensory-perceptual, personal and professional levels. Sensory-perceptual level is determined by appropriate lighting and noise level during works execution and is identified at certain kinds of individual's activity (emotional, practical, cognitive etc). At the basis thereof is activated the personal level of factors during which the person insensibly starts the process of knowing of certain information involving at that full range of cognitive processes, which is responsible for the ways of future processing of this information. The degree of activity of knowing will favour the formation of personal factors what is expressed in motivation for execution of professional tasks, which favours the formation of professional interest.

\section{Discussion}

Aviation technical maintenance works differ from other actions in aviation field with volume, complexity, necessary time, periodicity, place of execution, destination etc. It requires appropriate quantity of information that technical employees may and obliged to use in order to decrease the number of mistakes during execution of aviation technical maintenance.

It is important to note that human factor of aviation maintenance specialists manifests in: mistakes during study, difficulty in communicating, wrong selection of membership of professional group, unorganized teamwork, situational unawareness and weak leadership.

Concerning study in the field of human factor that being carried out according to the model MRM, here particular attention is paid to systematic nature of the work. At that the main aspects are social and organizational factors. Communication at the technical maintenance work is principally made indirectly through technical documentation, work cards, maintenance bulletins and other materials [12]. That is why engineering personnel is prevented from use of non-verbal means of communication, what complicates the interaction process between its participants. The membership of group of engineering personnel most commonly differs according to definite signs: education, experience, earlier work period. For this reason it is difficult enough to form teamwork skills between employees of this particular group.

Situational unawareness of technical personnel lies in the fact that there may be a disorder in the shop although the work conditions change slowly enough comparing to flying conditions. This is to say that technical personnel shall master situational unawareness and know how to extrapolate the consequences of mistakes within some hours, days or weeks. 
Very important for specialists of technical maintenance is acquisition of leadership skills. It is explained with the fact that at enterprises of technical maintenance the low-level managers or team manager often act as mediators in communication with multiple contact points in different departments and sections. That is why the managers of engineering personnel shall have skills not only of internal group behaviour (within heir groups), but also ability to communicate with outsiders, personnel of other shift, department, gang, which also differ with their experience, behaviour pattern etc.

Pursuant thereto it seems fair to say that the majority of reasons of mistakes of aviation maintenance specialists are related to inadvertence, nonobservance of technical discipline that may be caused by such human factors as fatigue, low motivation of the employee, low level of professional knowledge of technicians of maintenance and time shortage. All this is responsible for the presence of such mistakes during aviation technical maintenance as unsatisfactory execution of works related to the replacement of accessories, unsatisfactory execution of checking and adjustment as well as deficiencies of professional knowledge of specialists.

\section{Conclusions}

Identified particularities of human factor of professional activity of aviation maintenance specialists according to sensory-perceptual, personal and professional levels generate the need to search ways of improvement of this system in order to decrease human risk before making mistakes during execution of professional tasks. In our opinion, in order to solve this problem, aviation enterprises shall undertake relevant activities as to the improvement of quality of technical maintenance at sensorial, personal and professional levels. As to the first level it is necessary: to assure appropriate lighting of spaces corresponding to standards of functioning of visual analyzer; to decrease noise level by creating noise insulation between shops or provide the specialists with personal equipment of acoustic analyzer protection; to organize systematically occupational health examination of personnel in order to identify abnormalities of analyzers functioning, timely prevention of certain problems as to their work and general well-being; to regulate working hours according to provided standards; fix working hours for each employee with clear alternation of shifts (night - day) and not to violate them in no way.

In order to regulate factors of personal level it is necessary: to assure decent salary for the employee of this field; to introduce in the collective certain traditions, standards, rules and sanctions for its members; to develop corporate culture among employees; to demonstrate, from the part of management of the enterprise and team managers, respect of each employee regardless of his work experience, social status, education, gender and age; to organize psychological support service the specialists of which would perform work in different directions: diagnostic, correctional, precautionary, therapeutic etc. [2]

In order to organize the work as to the increase of professional motivation of aviation technical personnel, the executive management shall: control full-time personnel as to the education level; systematically undertake activities for improvement of qualification level according to regulatory instruments corresponding to its position; diversify types of professional training of personnel; favour and support innovation approaches of production tasks resolving by the personnel; diversify forms and kinds of professional training of personnel trough modern technologies of training.

Pursuant thereto it seems fair to say that considering of human factor of aviation maintenance specialists shall include: promotion of development of knowledge and skills of specialists of aviation field; assurance of corresponding professional level; investing in human capital; assuring of equal opportunities; objectivity during evaluation of work activity 
results; effective career management; stimulation of quality during tasks execution by aviation maintenance specialists; improvement of motivation system etc.

Consequently, investing in human factor in aviation field is an agreement beneficial enough between aviation enterprise, personnel, which is working there and society. And actions directed to its improvement, especially at sensory-perceptual, personal and professional levels increase work productivity and, consequently, decrease the risk of making mistakes at any level of their committing.

\section{References}

1. A.D. Artemov, N.D. Lysakov, E.N. Lysakova, The human factor in the operation of aircraft (2018)

2. A.V. Bogomolov, G.A. Sviridyuk, A.V. Keller, V.N. Zinkin, M.D. Alekhin, Third International Conference on Human Factors in Complex Technical Systems and Environments (ERGO)s and Environments (ERGO), 106-110 (2018)

3. V.I. Burlakov, Iu.P. Puchkov, O.V. Popov, Human factor in system of aviation flying ability preservation (2018)

4. N.M. Dobrotvorskyi, Gazette of air fleet 1, 28-35 (1937)

5. D.V. Gander, M.S. Alekseenko, A.A. Dolgov, Human factor: problems of psychology and ergonomics 1(86), 40-46 (2018)

6. Reporting documents of National Bureau of Air Accidents Investigation over the period 2015-2019

7. L.A. Kaidalov, Technology of prevention of aviation incidents at the basis of psychological potentials analysis of flight crews members (2017)

8. A.D. Artemov, N.D. Lysakov, E.N. Lysakova, Human factor in exploitation of aeronautic equipment (2018)

9. V.I. Lebedev, Individual in extreme conditions (1989)

10. L.V. Pomytkina, O.V. Girchuk, E.A. Pomytkin, The Eighth World Congress "AVIATION IN THE XXI-st CENTURY» - "Safety in Aviation and Space Technologies", 13.2.36-13.2.40 (2018)

11. L. Vinogradov, V. Shestakov, L. Buzhinsky, Scientific proceedings $x x$ international scientific-technical conference "trans \& motauto 12, 122-123 (2012)

12. L. Pomytkina, A. Gudmanian, O. Kovtun, S. Yahodzinskyi, International science conference 'Topical Problems of Green Architecture, Civil and Environmental Engineering' 164, 10021 (2020) https://doi.org/10.1051/e3sconf/202016410021 